\title{
Heat Stress as a Source of Infertility in Cattle Production
}

\section{Torrens $\mathrm{F}^{1}$, Marahatta $\mathrm{S}^{2}$, Duran $\mathrm{IL}^{3}$ and Ahaotu EO ${ }^{4 *}$}

${ }^{1}$ Department of Physical Chemistry, Universitat de València, Spain

${ }^{2}$ Department of Biological Sciences, Agriculture and Forestry University, Nepal

${ }^{3}$ College of Graduate Studies Don Mariano Marcos Memorial State University, Philippines

${ }^{4}$ Department of Animal Production Technology, Imo State Polytechnic Umuagwo, Nigeria

*Corresponding Author: Ahaotu EO, Department of Animal Production Technology, Imo State Polytechnic Umuagwo, Nigeria.

Received: June 13, 2019; Published: July 17, 2019

DOI: 10.31080/ASAG.2019.03.0578

\begin{abstract}
Climate change negatively affects livestock production and health. Cattle are kept for milk, meat, draught power and leather production in many developing countries. Due to ineffective cooling mechanisms like scanty sweat glands and hair coat they are more predisposed to heat stress causing huge economic losses to the cattle breeders. The heat stress primarily affects the hypothalamic-hypophyseal-ovarian axis and it is the interplay of endocrinological imbalances which affects the reproductive cycle causing seasonality and anoestrus. Hence heat stress needs to be averted so as to maintain the reproductive efficiency in cattle and prevent economic losses.
\end{abstract}

Keywords: Reproductive Efficiency; Heat Stress; Anoestrus; Cattle; Infertility

\section{Introduction}

Animals go through heat stress (HS) when the body temperature is higher than the optimal range specified for the normal activity because the total heat load is greater than the capacity for heat dissipation [1]. The heat stressed animals as observed in temperate is in the range from 5 to 150C [2]. Nardone., et al. [3] revealed that significant changes in feed intake and physiological processes occur with temperatures greater than 250C. However, heat stress changes as environmental humidity, air speed, genotype, physiological state, thermal susceptibility, acclimation and diets fluctuates. Animals attempt to maintain the body temperature increasing heat loss and reducing heat production by physiological and behavioural responses.

High environmental temperature challenges the animal's ability to maintain energy, thermal, water, hormonal and mineral balance. High ambient temperature and humidity are the major constant on cattle productivity in tropical and subtropical areas. Cattle can withstand for hours an external temperature as high as $43^{\circ} \mathrm{C}$ dur- ing which both sweating and panting are important heat regulating mechanisms. Cattle have immense production potential in terms of milk and meat and act as a source of sustenance to the poor in the developing world $[4,5]$. Cattle alone contributes approximately $96.8 \%$ of the total milk to the dairy industry in Asia and approximately $12.8 \%$ of the total world milk production though it forms only $11.6 \%$ of the total bovine population in the world [6].

In tropical and sub-tropical areas, indigenous cattle tend to breed throughout the year, although the sexual activity is restricted to a certain extent to the dry season [7]. This effect is aggravated when heat stress is accompanied by high ambient humidity. Exposure of cattle to elevated temperatures results in a decrease of body weight, average daily gain, growth rate and body total solids, which is reflected by impaired reproduction [8].

Cattle are efficient converter of poor quality and fibrous feeds into high quality protein like meat, milk and valuable by-products [9]. Agarwal., et al. [10] stated that due to the better digestive ability cattle can utilize poor quality roughage and convert into high 
quality protein. Climatic factors such as air temperature, solar radiation, relative humidity, air flow and their interactions, often limit animal performance [11].

Elevated body temperatures have significant effect on the physiological systems governing thermal balance of the animal thus maintaining positive heat loss for efficient cooling. In tropical and subtropical areas, high ambient temperature is the major constraint on animal productivity $[8,12]$. High ambient humidity aggravates the effect of heat stress [12] as it prevents evaporative cooling which is the last resort for the animal when ambient temperature rises to a higher level.

Exposure of cattle and other animals to the hot conditions evokes a series of drastic changes in the biological functions that include depression in feed intake, efficiency and utilization, disturbances in metabolism of water, protein, energy and mineral balances, enzymatic reactions, hormonal secretions and blood metabolites [13]. Such changes result in impairment of reproduction and production performances. Heat stress directly affects the reproductive efficiency of cows and reduces the intensity and duration of oestrus.

\section{Effect of heat stress on the females reproductive traits}

\section{Oestrus}

Heat stress directly affects oestrus. When the ambient temperature is low in morning and evening, maximum display of sexual activity occur whereas lowest activity is seen in the afternoon. ElWardani and El-Asheeri [14] observed that the cows exhibited the signs of oestrus in the early morning (3.00 to 9.00 hours) and in the evening (15.00 to 21.00 hours) with a peak in early morning (about $37 \%$ ), while the lower percentage was at noon (about $12 \%$ of oestrous cases started during the period from 9.00 to $15.00 \mathrm{~h}$ ). Ovarian activity decreases in tropical environment as well as, anoestrum is produced [14] due to heat stress. The decline in feed intake and in the quantity and quality of feed may, aggravate the negative influence on the adeno-hypophysis during dry season in cattle which result in less gonadotrophic hormone release and anoestrum.

Length of oestrous cycle and degree of expression of oestrus in cows are affected by various factors such as season, climate, photoperiod, temperature and nutrition [14]. Collier., et al. [15] reported that heat stress increased the ACTH/cortisol level, which caused a change in the endocrine secretion resulting in anoestrus.

\section{Silent heat}

Dokladny., et al. [16] reported that silent heat in cattle may be due to the anoestrus caused by thermal stress. Decrease in estradiol level in the hot season leads to depressed manifestation of oestrus especially on the day of estrous resulting in quiet ovulation and ovarian activity delay in cattle [15]. Caroprese., et al. [17] reported that higher incidence of the silent heat in cattle calving during the hot season (35.7\%) than in those calving in the mild season $(27.3 \%)$.

\section{Pregnancy rate}

The decrease in estrogen concentration as a function of heat stress and, consequently, the sufficient alteration of environment in the follicle suppresses normal maturation of the egg with depression of (luteinizing hormone) LH. Liu., et al. [18] showed rising ambient temperature from 12.5 to $35^{\circ} \mathrm{C}$ was accompanied by decline of CR in cattle from 40 to $31 \%$ and an increase in rectal temperature of $1^{\circ} \mathrm{C}$ at $12 \mathrm{~h}$ post insemination was found to be associated with a decrease of CR in cattle (45 vs. 61\%) [19]. The high adverse effects in females are shown on the ova, their fertilization and consequent development of embryos [20].

\section{Effect of heat stress on ovarian function}

Some early studies reported no quiescence of reproductive rhythm [18] evident by the presence of follicular growth followed by atresia [21]. Nanda., et al. (2003) indicated that there was the presence of quiescent ovaries in most cattle in hot season months. Morphological and histo-chemical studies revealed both normal as well as atretic follicles of variable sizes in atretic cattle ovaries [22]. Neglia., et al. [23] reported the higher sensitivity of cattle oocytes due to heat stress. It has been reported that season has significant effect on cattle oocyte yield and quality [24].

\section{Effect of heat stress on the hormonal profile}

Heat stress is directly known to affect the neuroendocrine setup in cattle [17]. They are very susceptible to thermal stress [22] during hot season because of poor evaporative cooling mechanism owing to scanty sweat glands. Scanty hair coat also is unable to provide effective protection against the thermal stress and high relative humidity further aggravates the condition [25]. The heat stress causes hyper-prolactinemia, reduced luteinizing hormone (LH) frequency, poor follicle maturation and decreased oestradiol production in anoestrus cattle [15] leading to ovarian inactivity. 
The circadian secretion of melatonin from the pineal gland adds to the seasonal effects [26]. The following endocrinological factors are influencing seasonal reproduction in cows.

\section{Photoperiodism and role of melatonin}

Melatonin secretion is the hormonal signal of light dark rhythm. Although cattle are polyestrous, they exhibit seasonality in displaying estrous in which, photoperiod depending on secretion of melatonin plays a major role [15]. More seasonal cattle are reported to have high concentration of melatonin after sunset [27]. Chedid., et al. [28] also reported remarkable changes in melatonin levels in cattle heifers.

\section{Hyperprolactinemia}

Seasonal changes in pineal metabolism leads to hyper-prolactinemia during heat stress [7] which prevents LH secretion caused by positive feedback of estrogen at hypothalamic level [29] while at ovarian level it alters the level of $\mathrm{LH}$ receptors leading to anoestrus in summer.

\section{Lack of LH surge and low levels of FSH}

Peripheral FSH concentrations [26] and LH levels are affected by weather [25]. In cattle, FSH concentrations were reported to be higher at oestrus and during luteal phase in November to December in comparison to March to June [30]. Similarly peak LH levels were found to be higher in cooler months [16]. It is reported that lower basal LH levels and lack of pre-ovulatory surge are associated with ovarian inactivity in summer [31]. Decrease in LH peak and lower progesterone concentration may be responsible for silent oestrus in hot season [25].

\section{Role of progesterone}

Significantly higher progesterone concentrations have been found in hot climate than in cold weather [32]. These high concentrations could be attributed to release of progesterone from adrenal cortex induced by heat stress under prolonged heat exposure [30]. Progesterone concentrations are also found to vary with nutritional status of the animal which coupled with heat stress can lead to long anoestrus in cattle.

Heat stress causing low level of thyroid hormones or hypothyroidism has been associated with reduced responsiveness of the ovary to FSH and LH leading to hot season anoestrus [33]. Similarly, high level of corticosteroids in serum produced in response to thermal stress leads to change in secretion pattern of pituitary gonadotropins causing a state of anoestrus [34]. Heat stress, could impact on meat safety as well as organoleptic quality. Global warming could affect microbial burdens on carcasses and meat, especially if the animals carry more enteric pathogens in their gut or on their body surface. Extreme heat provokes an adrenergic stress response. Adrenaline stimulates peripheral vasodilatation and muscle glyco-genolysis, and if exposure is protracted before slaughter it could lead to high $\mathrm{pH}$ and darker meat.

\section{Conclusions}

Heat stress is becoming a serious problem because of the negative impacts on ruminant performance. The negative effect of HS will become more severe in the future, as a consequence of global warming progresses and genetic selection for milk yield continues. Heat-stressed animals change their metabolism and physiology in response to weather change. The direct and indirect effects of HS affect gastrointestinal health and functionality strongly influencing the efficiency of diet utilisation. The changes in nutrient partitioning and the alteration of rumen and intestine functionality should be taken into account.

Cattle are perfectly suited to the hot season but they exhibit signs of great distress when exposed to direct solar radiation or when working in the sun during hot season. Heat stress affects male and female reproductive functions deleteriously causing seasonality in reproduction, silent heat coupled with poor expression of estrous and low conception rate.

Besides proper management in terms of feeding, housing to alleviate heat stress, a sound knowledge in terms of interplay of hypothalamic, gonadotropic and gonadal hormones in stress conditions, can help to devise means to improve reproductive performance in these animals. An endocrine balance is expected to improve reproductive efficiency.

\section{Bibliography}

1. Bernabucci U., et al. "Metabolic and hormonal acclimation to heat stress in domesticated ruminants". Animal 4 (2010): 1167-1183.

2. Hahn GL., et al. "Perspective on development of thermal indices for animal studies and management". EAAP 7 (2003): 31-44.

3. Nardone A., et al. "Effects of climate changes on animal production and sustainability of livestock systems". Livestock Science 130 (2010): 57-69. 
4. Javaid SB., et al. "Physical and chemical quality of market milk sold at Tandojam, Pakistan". Pakistan Veterinary Journal 29 (2009): 27-31.

5. Abdolghafour B and Saghir A. "Buffalo: a potential animal for quality meat production - a review". Livestock Research International 2 (2014): 19-29.

\section{FAOSTAT (2007).}

7. Kadim IT., et al. "The influence of seasonal temperatures on meat quality characteristics of hot-boned, m. psoas major and minor, from goats and sheep". Journal of Meat Science 80 (2007): 210-215.

8. Shelton M. "Reproductive performance of sheep exposed to hot environments". In: Sheep Production in Hot and Arid Zones, RC Malik, MA Razzaque and AY Al-Nasser (eds), Kuwait Institute for Scientific Research (2000): 155-162.

9. Kandeepan G., et al. "Processing characteristics of buffalo meat - a review". Journal of Meat Science and Technology 1 (2013): 01-11.

10. Agarwal N., et al. "Effect of peppermint (Mentha piperita) oil on in vitro methanogenesis and fermentation of feed with buffalo rumen liquor". Animal Feed Science and Technology 148 (2009): 321-327.

11. Mishra A., et al. "Effect of oxidative stress on animal reproduction". Livestock Research International 3 (2015a): 103-109.

12. Marai IFM., et al. "Reproductive performance traits as affected by heat stress and its alleviation in sheep - a review". Tropical and Subtropical Agro ecosystems 8 (2008): 209-234.

13. Mishra A., et al. "Modern concept in optimizing reproductive efficiency of seasonal breeders". Livestock Research International 3 (2015b): 51-57.

14. El-Wardani MA and El-Asheeri K. "Influence of season and number of heat checks on detecting of ovulatory estrus in Egyptian buffaloes". Egyptian Journal of Animal Production 37 (2000): 18-22.

15. Collier RJ., et al. "Major advances associated with environmental effects on dairy cattle". Journal of Dairy Science 89 (2006): 1244-1253.

16. Dokladny K., et al. "Physiologically relevant increase in temperature causes an increase in intestinal epithelial tight junction permeability". American Journal of Physiology-Gastrointestinal and Liver Physiology 290 (2006): G204-G212.
17. Caroprese M., et al. "Dietary glutamine enhances immune responses of dairy cows under high ambient temperature". Journal of Dairy Science 96 (2013): 3002-3011.

18. Liu DY., et al. "Effect of daidzein on production performance and serum anti-oxidative function in late lactation cows under heat stress". Livestock Science 152 (2013): 16-20.

19. Berman A. "Invited review: are adaptations present to support dairy cattle productivity in warm climates?" Journal of Dairy Science 94 (2011): 2147-2158.

20. Berman A. "Extending the potential of evaporative cooling for heat-stress relief". Journal of Dairy Science 89 (2006): 38173825 .

21. Liu F., et al. "Selenium and vitamin E together improve intestinal epithelial barrier function and alleviate oxidative stress in heat-stressed pigs". Experimental Physiology 101 (2016): 801-810.

22. Calamari L., et al. "Effects of different feeding time and frequency on metabolic conditions and milk production in heatstressed dairy cows". International Journal of Biometeorology 57 (2013): 785-796.

23. Neglia G., et al. "Influence of a swimming pool on fertility in buffalo species". Italian Journal of Animal Science 8 (2009): 637-639.

24. Zoheir KMA., et al. "Effects of season on the quality and in vitro maturation rate of Egyptian buffalo (Bubalus bubali) oocytes". Journal of Cell and Animal Biology 1 (2007): 29-33.

25. Ammer S., et al. "Comparison of different measuring methods for body temperature in lactating cows under different climatic conditions". Journal of Dairy Research 83 (2016): 165-172.

26. Ronchi B., et al. "Influence of heat stress or feed restriction on plasma P4, oestradiol $17 \alpha, \mathrm{LH}, \mathrm{FSH}$, prolactin and cortisol in Holstein heifers". Livestock Production Science 68 (2001): 231-241.

27. Chase LE. "Climate change impacts on dairy cattle". Fact sheet, Climate Change and Agriculture: Promoting Practical and Profitable Responses (2006).

28. Chedid M., et al. "Review: water stress in sheep raised under arid conditions". Canadian Journal of Animal Science 94 (2014): 243-257. 
29. Kadim IT., et al. "Effects of transportation at high ambient temperatures on physiological responses, carcass and meat quality characteristics of three breeds of Omani goats". Journal of Meat Science 73 (2006): 626-634.

30. Yousefi AR., et al. "Comparison of the meat quality and fatty acid composition of traditional fat-tailed (Chall) and tailed (Zel) Iranian sheep breeds". Journal of Meat Science 92 (2012): 417-422.

31. Diesel B., et al. "a-Lipoic acid as a directly binding activator of the insulin receptor: protection from hepatocyte apoptosis". Biochemistry 46 (2007): 2146-2155.

32. Mondal S., et al. "Influence of season on peripheral plasma progesterone in cycling Murrah buffaloes (Bubalus bubalis)". Buffalo Journal 1 (2004): 95-100.

33. Al-Dawood A. "Effect of heat stress on adipokines and some blood metabolites in goats from Jordan". Animal Science Journal 88 (2017): 356-363.

34. Abeni F and Galli A. "Monitoring cow activity and rumination time for an early detection of heat stress in dairy cow". International Journal of Biometeorology 61 (2016): 417-425.

Volume 3 Issue 8 August 2019

(c) All rights are reserved by Ahaotu EO., et al. 